\title{
Electric Vehicle Charge Stations Location Analysis and Determination-Ankara (Turkey) Case Study
}

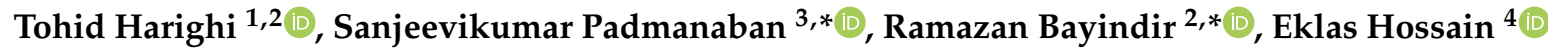 \\ and Jens Bo Holm-Nielsen ${ }^{3}$ \\ 1 Graduate School of Natural and Applied Sciences, Gazi University, 06500 Ankara, Turkey \\ 2 Department of Electrical and Electronics Engineering, Faculty of Technology, Gazi University, \\ 06500 Ankara, Turkey \\ 3 Center for Bioenergy and Green Engineering, Department of Energy Technology, Aalborg University, \\ 6700 Esbjerg, Denmark \\ 4 Oregon Renewable Energy Center (OREC), Department of Electrical Engineering \& Renewable Energy, \\ Oregon Tech, Klamath Falls, OR 97601, USA \\ * Correspondence: san@et.aau.dk (S.P.); bayindir@gazi.edu.tr (R.B.); Tel.: +45-2097-5179(S.P.)
}

Received: 4 July 2019; Accepted: 2 September 2019; Published: 9 September 2019

\begin{abstract}
Locating electric vehicle charge stations has always been an important problem for electric distributers. Many basic and complex solutions have been provided by algorithms and methods to solve this problem in real and assumed grids. However, the data, which has been used in those algorithms, are not consistent with the diversity of locations, thus, do not meet the expected results. Grid locations are the most important aspects of this issue in the eyes of designers, investors, and the general public. Locating charge stations must be determined by plans which have influenced majority in the society. In some countries, power quality has been increased by storages, which are used in vehicle-to-grid (V2G) and similar operations. In this paper, all of the variables for locating charging stations are explained according to Ankara metropolitan. During the implemented analysis and literature reviews, an algorithm, based on location and grid priorities and infrastructures, are $154 \mathrm{kV}$ and $33 \mathrm{kV}$, have been designed. Genetic algorithms have been used to demonstrate this method even though other algorithms can also be adopted to meet the priority.
\end{abstract}

Keywords: electric vehicles; charging station; transformer; Energy PLAN; grid; renewable energy

\section{Introduction}

Charging stations or other types of energy storages need organization when they are used for special targets. Considering the grid's situation, an organized program should cover the supply and demand needs of the grid. Supply needs, such as low loss operation without side effects, and demand needs, such as abundance in the charge station, low cost, and increased power quality, are required to be fulfilled. All of these needs and similar problems, issues or remodeling methods have created a basis to providing organization for electric vehicles (EV) charge stations. Factors, such as societal, populace, grid infrastructure, and renewable conditions [1], critical power range, and financial analysis of a location, play important roles in determining the grid condition. However, supply/demand power and coordination, and the estimation of equipment is the telling factor, which needs focus to meet the incessant load demand.

The estimation of power, especially on the demand side of the grid, is very difficult [2]. Increasing or decreasing the rate of grid power does not go on determined patents, such as battery open circuit voltage estimation by Extended Kalman Filter (EKF) or similar estimation operations [3]. Supply/demand and coordinating for EVs charge station estimations have a lot in common, so they can contribute to an 
increase in power quality in the grid, directly when the grid infrastructure is ready. The benefits of this work are not limited to some factors, such as the decrease in green-house gas (GHG) emissions. Fuel transmission between oil refineries to gas stations consume electric power, especially in gas stations where compressed natural gas (CNG) stations use electric convertors. At present, too many researchers are trying to create and optimize algorithms to harvest fine results, but the methods and algorithms should be fed by trustworthy numerical data. In addition, the experiments are to be simulated using simulation software, such as MATLAB. In one Finnish study, to meet Finland's target of $100 \%$ renewable energy usage by 2050's (funded and presented by Ministry of Economy and Employment), the research on Energy PLAN (created by Aalborg University) modelling has focused on energy potential and generation from a perspective of economy, the rate of fuel usage, and $\mathrm{CO}_{2}$ emission according to decrease in GHG emission policy [4]. The result of this investigation shows that the energy future, based on 100\% renewable energy, is entirely possible. In another study focused on Delhi, India's energy sector, the Japanese Society for the Promotion of Science (JSPS) investigated the future of energy and its optimization methods in Delhi. Their study found that integrated-systematic modelling should be used for energy flow in urban energy systems. They have used an optimal energy scenario and found an energy gap between supply and demand. This research paid attention to government energy policy in improving the demand side of their energy sector [5]. However, government policy and social behavior strongly influence the GHG emission in the transportation sector, in many countries, such as Austria [5]. The emission of $\mathrm{CO}_{2}$ is one of the primary problems in China and the $\mathrm{CO}_{2}$ condition will be in 2030 with the use of control or uncontrolled EVs, V2G and similar transportation systems. Studies have shown that the application of these transportation systems provide advantages, such as decreasing peak load, which is used for EV charging; generating power from renewable energy sources (RES); and reducing energy generation and EV charging costs [6]. Some of the literature has focused on the distance of charge stations with respect to the most capable grids. A Taiwanese study looked into helping customers receive better service from the grid by creating charge stations at reasonable distances in Taiwan [7]. Therefore, it is possible to determine probable locations for EV charging stations, based on the grid and transportation technology of the time, rather than based on any specific algorithm.

Several algorithm-based research are still used in smart grid and V2G operations for special conditions or purposes which are explained below. One study focused on uncertain situations with respect to V2G operation pricing, using the robust game-theory to treat uncertain issues. This algorithm was named ENTRUST (Energy Trading under Uncertainty in Smart Grid Systems) [8]. This study achieved reliability and cost efficiency in terms of energy management. Another grid lead system is known as multi-agent energy management. In this system, all elements of demand side of the grid (home, building, industries, and vehicles) are connected. It can improve autonomy, connectivity, diversity, and appearance of the systems in the grid. Another study in Great Britain (GB) [9], created a dynamic virtual energy storage systems (VESS) to solve the dynamic frequency response. This model uses V2G and similar technology storages to notify grid whenever it needs emergency energy or whenever the rhythm of the energy flow has been disturbed. This model considered the response capacity of an EVs cluster. Researchers have furthermore developed some algorithms for EV charge stations, including the flow refueling location model (FRLM) [10] maximum covering location problem (MCLP) [11], nonlinear auto-regressive (NAR) [12], Genetic Algorithm (GA) [13], Genetic Algorithm-particle swarm optimization (GA-PSO) [14], and Genetic Algorithm-binary particle swarm optimization (GA-BPSO) [15].

Each research has coordinated points by special parameters, which is the dominant factor in supporting the system objectives. Previously described models, scenarios, and algorithms are the key to managing the grid and to increasing responsibility for EVs, charge stations and interconnected storage. The coordination of EV charging stations at first sight needs these methods to solve some pre-requisites. This paper considers Ankara's metropolitan electric infrastructure and the conditions dependent on Ankara's electricity infrastructure to determine potential locations for the charging 
stations. In Ankara's case, the grid has not been updated to be smart enough to include online sensors, which may be used in determined algorithms. This study attempts to determine the location by specifications of the grid infrastructure, categorizing the capacity of transformers and their other parameters. A method, based on the Genetic Algorithm is designed to verify the probability of a location meeting the requirement is shown.

The rest of the paper is organized as follows. Section 2 discusses the case study, particularly considering four locations in Ankara. Section 3 takes grids in Ankara in consideration to nominate them as the station location. Section 4 brings transformers into inspection by delineating several parameters to select transformers capable of matching the EV application. Section 5 presents the corresponding transformer indices and parameters to aid the selection process. Considering this framework, the layout of the estimation algorithm with respect to the Genetic Algorithm is explained in Section 6. Finally, conclusions are drawn in Section 7.

\section{Case Study}

In this paper, four transformer centers have been considered at the start/end points, which are supplied by A point and finally used by $\mathrm{D}$ point. Each point has been analyzed by their maintenance history and current peak load point. Transformer maintenance history and current peak load point can illustrate most of their qualities. This research attempts to create a defined glance to recognize points, which are necessary for determining the location of EV charging stations, that can help to build a connection with the grid plan. In the next sections, the proposed solution for determining the coordination of EV charging stations will be elaborated with examples. Ankara metropolitan electricity grid is one of the real cases to study, indicating important parameters, when the grid should be ready to supply electric vehicle and storages.

As demonstrated in the literature, the categories of charging stations distance can change quality of power, service, cost and EVs technology acceptance ratio between members of society. The range of charging stations were determined by various items, such as the grid infrastructure and existing EVs going around. Additionally if the grid does not use charging stations, some locations should be determined by other specifications. These can be different in each grid and depends on the grid's condition. According to the previously mentioned information and Ankara metropolitan electricity infrastructure, the distance of grid terminals and power capacity are critical points in the coordination of electric vehicle charge station topic. A city's transportation routes are different from the route of the power transmission grid and each location has specific power capacity details. In the first step, designers must select locations like points or places, which have the lowest distance to electricity terminals and are suitable for transportation systems. The goal is to measure energy, and responsibility for supply and demand. For example, two different points in Ankara have been assessed - the A and B transformer centers. Both of them are on main and crowded streets, but the A transformer center's condition makes it more operational than the B transformer center. This is, because the A transformer center is close to downtown where the main transportation terminals, such as buses and trains are localized. Whereas 1 2 km from downtown, metro, terminals and location of transformer A and B have many free spaces, parking, schools, hospitals and ministries. It seems that in this area, a large amount of vehicles are stationary and this can be potentially beneficial. In contrast, the B transformer center does not have those options, and because of this, the B transformer center loses its priority to build a charging station. Figure 1 has given the locations of both transformer centers and a map of Ankara for clarity.

Location EV charge station points should be categorized by reasonable distances such as 30,35 , 40,45 , and $50 \mathrm{~km}$, depending on area and infrastructure condition. In the mentioned case, the grid conditions were analyzed, based on the transformer status, even though there was no pre-defined storage center or organized charge station. This indicates that transformer specifications could provide prospective information to evaluate the likelihood of charging stations. 


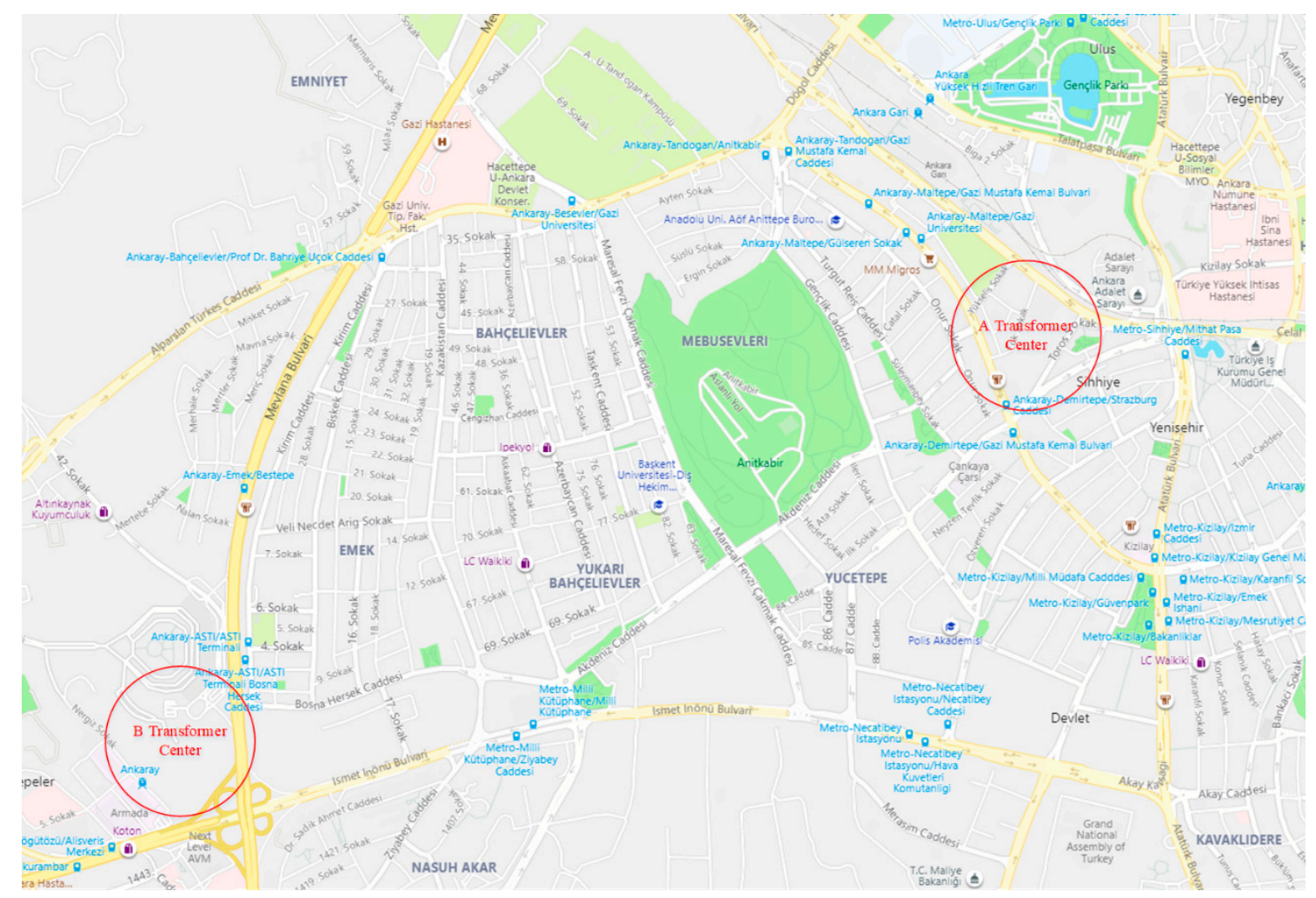

Figure 1. Map of Ankara, and area maps of the A and the B Transformer Centers [16].

\section{Grid Conditions in Ankara}

One of the important factors in grid stability is its dependency on the grid size and infrastructure revises, but efficiency and responsibility are negotiable. The electricity grid of the provinces of Ankara, Bartın, Çankırı, Karabük, Kastamonu, Kırıkkale, and Zonguldak are controlled by the ENERJISA Company (Hanımeli Avenue No:1 Sihhiye/ANKARA) [17]. At first, the stability of grid should be examined with respect to power and size. This area has special specifics, which help to stabilize the grid. As the area is located in the middle of Turkey and neighbors the five other grid control areas, Ankara can receive energy from five different electricity areas, which means that this area has enough reserve power from the Turkish National Grid. This area is formed from provinces, which have an energy generation rate more than their consumption rate. Some information about those provinces are shown in Table 1.

Table 1. Some energy consume and generate details of province which are under the control of ankara province [18].

\begin{tabular}{lccc}
\hline & Power Plants Quantity & $\begin{array}{c}\text { Annual Consumed } \\
\text { Energy Rate in Turkey }\end{array}$ & $\begin{array}{c}\text { Annual Energy } \\
\text { Generation in Turkey }\end{array}$ \\
\hline Ankara & 69 & $3.64 \%$ & $\sim 9.299 \mathrm{GWh}$ \\
Kırıkkale & 9 & $3.44 \%$ & $\sim 8.797 \mathrm{GWh}$ \\
Zonguldak & 7 & $4.10 \%$ & $\sim 13.332 \mathrm{GWh}$ \\
Kastamonu & 10 & $0.07 \%$ & $\sim 188 \mathrm{GWh}$ \\
Çankırı & 3 & $0.01 \%$ & $\sim 14 \mathrm{GWh}$ \\
Karabük & 7 & $0.22 \%$ & $\sim 575 \mathrm{GWh}$ \\
Bartın & 3 & $0.02 \%$ & $\sim 56 \mathrm{GWh}$ \\
\hline
\end{tabular}

The grid has been shown to be stable at high penetration rate. The energy terminals are in special places, where they can provide high performance in particular aspects such as energy responsibility. However, they cannot exceed an appropriate amount, which are key points in the energy transfer 
between grids and storage, thus, both of their accessibilities observe different purposes. Figure 2 illustrates this point clearly. Generally, bi-directional energy transfer has been operated between medium voltage and low voltage range. Bi-directional operation procedures develop in parallel with grid infrastructure and customers.

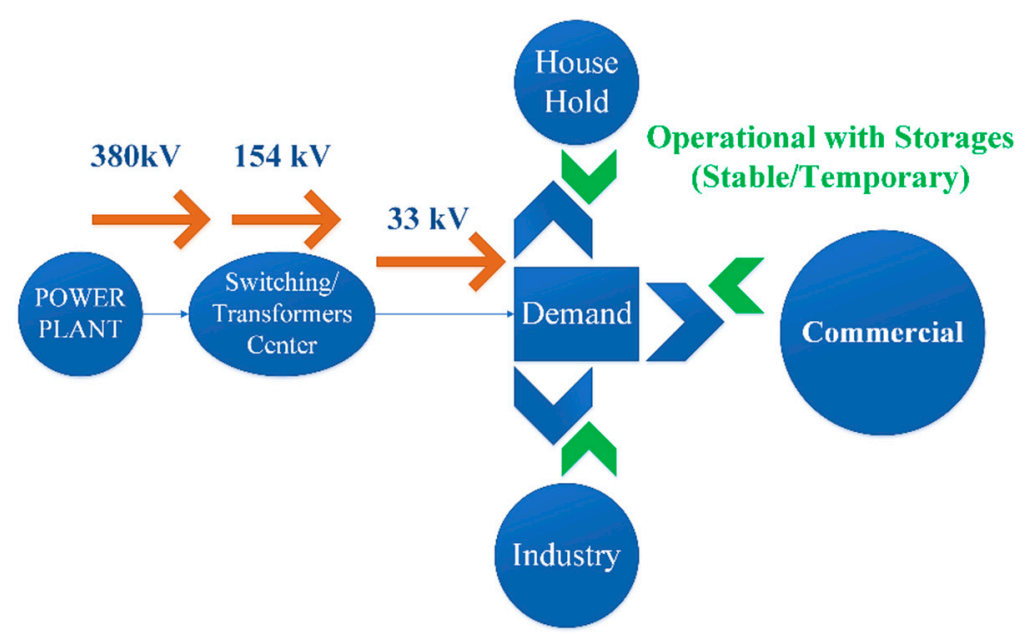

Figure 2. Energy injection side and areas can be operational by storages.

\section{Transformer Selection}

Transformers are the last operational part of the grid, which directly influence the quality of the grid and charge stations. Generally, all ranges of grid transformers are influenced by storages, such as charging stations or grid independent storages. Low- and mid-range transformers in the grid receive high impact from power electronic equipment, but they need support from high voltage transformers. Some transformer parameters depend on their own operational period, which cannot be determined in routine ways. The capacity of distribution in transformers has the potential to determine the necessary variables in the grid, related to financial problems, aging, health, and their priorities. Hence in this algorithm, the capacity and related problems have a higher priority. Low capacity or overload is the first step in system failure. Overload in electric equipment, like transformers, cause severe faults in the grid. In the second step, it causes a nonlinear increase in the transformers' temperature [19]. One of the regular solutions to solve these problems is by decreasing or changing the load pattern according to different grid specifications [20]. Transformers should be sorted according to their capacity. The flow chart of sorting is shown in Figure 3.

The purpose is to determine high priority transformers in the grid. By changing the timeslot in the Grid Valley filling technology [21], grid demand level, load factor, and transformer aging have been changed at a reasonable scales. It can reduce load about $4 \sim 5 \mathrm{GW}$ in a scenario and ambient transformers temperature 1.06 1.64\% instead 52 100\% in $50 \mathrm{kVA}$ transformers and $200{ }^{\circ} \mathrm{C}$ temperature rate. Consequently, transformer aging is influenced with these statistics, where it has changed 17 18 factors, instead of 17 96. Another study has illustrated that EVs generate overload and shape impulses. Such grid problems have been solved through timetable changes and transformer hierarchy, as shown by MATLAB V9.5 software [22,23]. The solving method can change in each location, depending on related problem conditions, therefore, there (There will be various conditions at hand). The smart grid transmission and distribution costs are very important and have been influential in the other side of the grid. The function of transmission and distribution costs has been given in 
Equation (1) [24]. Equation (1) has illustrated the importance of grid infrastructure and equipment costs when they have met low/over load. In this equation transformers and lines are the main factors [24].

$$
\begin{aligned}
\text { Min } \mathrm{z}= & \sum_{(\mathrm{i}, \mathrm{j}) \in \text { Line }} \mathrm{a}_{\mathrm{i}, \mathrm{j}}\left(\mathrm{X}_{\mathrm{i}, \mathrm{j}}\right)+\sum_{(\mathrm{i}, \mathrm{j}) \in \text { OverLine }} \mathrm{b}_{\mathrm{i}, \mathrm{j}}\left(\mathrm{X}_{\mathrm{i}, \mathrm{j}}\right)+ \\
& \sum_{\mathrm{m} \in \text { Over Equip }} \mathrm{c}_{\mathrm{m}}\left(\mathrm{X}_{\mathrm{m}}\right)+\sum_{\mathrm{n} \in \text { OutLoad }} \mathrm{d}_{\mathrm{n}}\left(\mathrm{X}_{\mathrm{n}}\right)+ \\
& \sum_{\mathrm{n} \in \text { OutLoad }} \mathrm{e}_{\mathrm{n}}\left(\mathrm{X}_{\mathrm{n}}\right)+\sum_{\mathrm{m} \in \text { Ment Equip }} \mathrm{f}_{\mathrm{m}}\left(\mathrm{X}_{\mathrm{m}}\right)+ \\
& \sum_{\mathrm{k} \in \text { Power Equip }} \mathrm{g}_{\mathrm{k}}\left(\mathrm{X}_{\mathrm{k}}\right)+\sum_{\mathrm{m} \in \text { Fail Equip }} \mathrm{h}_{\mathrm{m}}\left(\mathrm{X}_{\mathrm{m}}\right)
\end{aligned}
$$

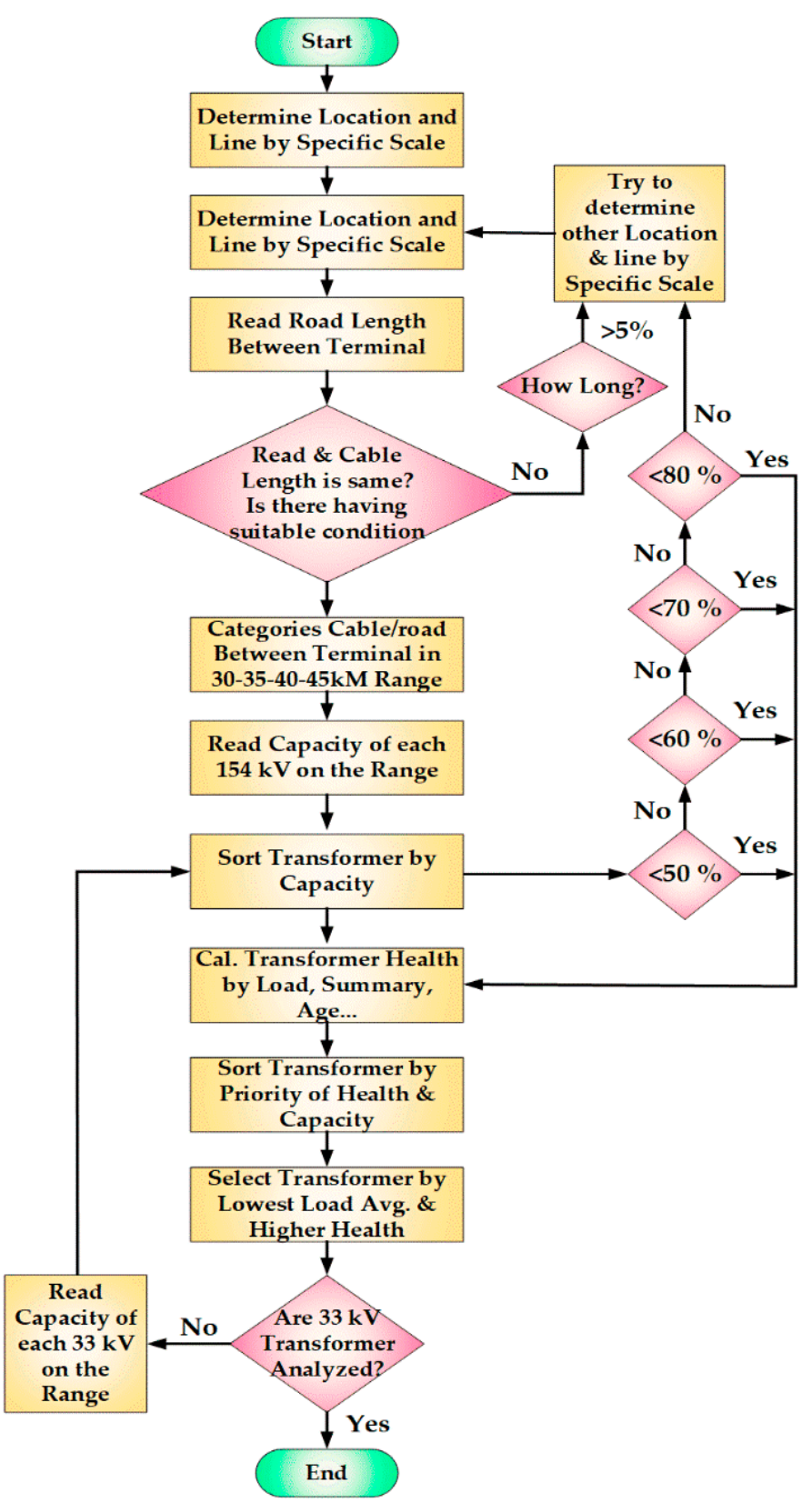

Figure 3. Electric vehicle (EV) charge stations coordination algorithm.

The above equation shows that transmission and distribution costs create a large part of the grid's maintenance cost. The next equations have illustrated aging and the loss of life rate of the transformer for 
an average penetration rate of EV $[25,26]$, which completely depends on the transformers' temperature. Through various investigations, EV fast charge stations or similar loads were found to generate an impulse load signal type, consequently, it hides hot-spot temperature points in the transformer, which sensors cannot detect.

$$
\begin{aligned}
& \mathrm{V}=\mathrm{e}^{\frac{15000}{110+273}-\frac{15000}{\theta_{\mathrm{h}}+273}} \\
& \mathrm{~L}=\int_{\mathrm{t}_{1}}^{\mathrm{t}_{2}} \mathrm{Vdt} \text { Or } \mathrm{L} \approx \sum_{\mathrm{n}=1}^{\mathrm{N}} \mathrm{V}_{\mathrm{n}} \times \mathrm{t}_{\mathrm{n}} \\
& D_{T R \_P H E V \_X}=A \times e^{\left(B \times T_{x_{-}} T_{r}\right)} \\
& \mathrm{V}_{\text {TR_PHEV_X }}=\frac{\mathrm{D}_{\text {TR_PHEV_WITHOUT }}}{\mathrm{D}_{\text {TR_PHEV_X }}} \\
& \mathrm{V}_{\text {TR_PHEV_LOW }}=\mathrm{A} \times \mathrm{T}_{\mathrm{x}_{-}} \mathrm{T}_{\mathrm{r}}+\mathrm{B} \\
& V_{\text {TR_PHEV_X }}=A \times \mathrm{e}^{\left(B \times T_{x_{-}} T_{r}\right)}+C \times \mathrm{e}^{\left(D \times T_{x_{-}} T_{r}\right)}
\end{aligned}
$$

Figure 4 clearly shows the temperature influence on the loss of life (LOL) rate on transformers, which can be proved by Equations from (2) to (7) [25]. The transformers' overall condition is important when transformer temperature exceeds $110^{\circ} \mathrm{C}$, so the LOL rate starts increasing.

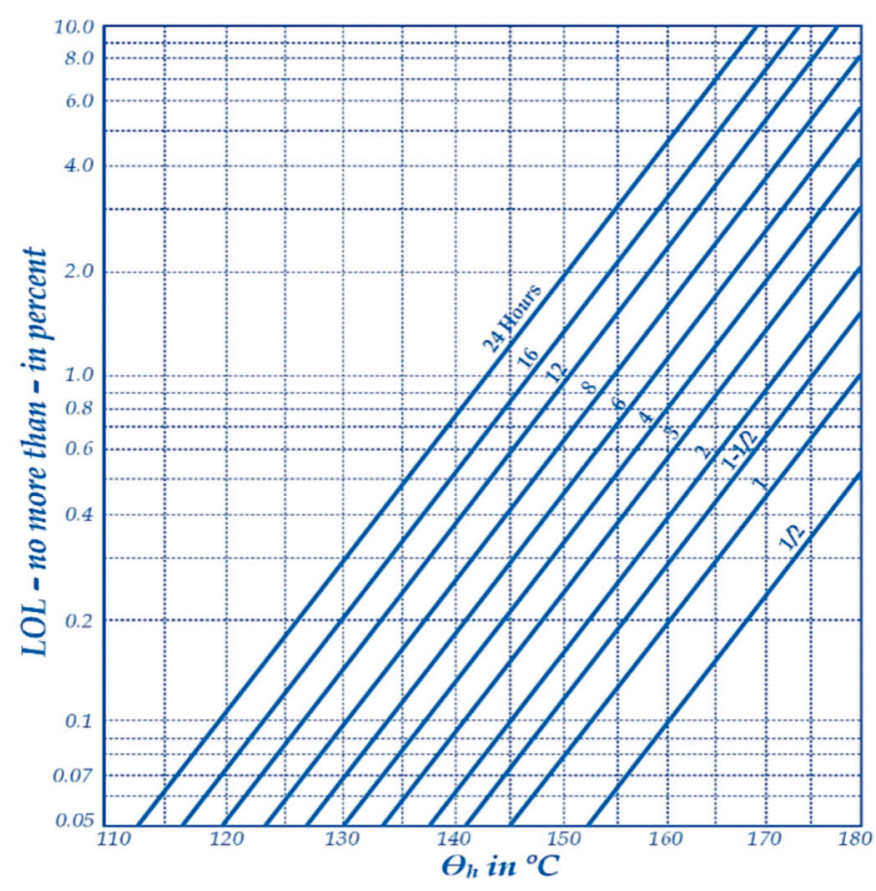

Figure 4. LOL and $\theta_{\mathrm{h}}$ in different time [25].

One of the most effective ways to solve this type of problem is to monitor transformer temperatures, which are controlled at SCADA or matched on relay settings [25]. Indisputably, sometimes by assigning more EVs in each grid, some transformers might get overloaded, consequently leading towards faults or interruptions in the grid. The solution to capacity problems depends on the grid communication infrastructure and the grid creation hierarchy. The flow chart of the grid communication infrastructure and the grid creation hierarchy is also represented in Figure 3.

According to the grid condition, there are many factors in the flowchart that can be calculated altogether. For Ankara, we do not have a smart transformer with online monitoring, therefore, we must use tools based on summary data. Table 2 shows information that owner $C$ and $D$ have a high priority to create a charge station on their locations. For example, the data of a grid with air quality sensor results are provided below. 
Table 2. A grid transformers' center and their environmental condition.

\begin{tabular}{|c|c|c|c|c|c|c|c|}
\hline \multicolumn{3}{|c|}{ Transformer Center } & \multicolumn{5}{|c|}{ Load } \\
\hline \multicolumn{3}{|c|}{ A } & \multicolumn{5}{|c|}{$649 \mathrm{MW}$} \\
\hline \multirow{2}{*}{\multicolumn{2}{|c|}{ Transformer Center }} & \multirow{4}{*}{$\begin{array}{c}\text { Load } \\
33.5 \\
58.5\end{array}$} & \multirow{4}{*}{\multicolumn{2}{|c|}{$\begin{array}{l}\text { Usage Percentage } \\
\qquad \begin{array}{c}62 \\
54\end{array}\end{array}$}} & \multirow{4}{*}{$\begin{array}{l}\text { Owner } \\
\text { A } \\
\text { A }\end{array}$} & \multicolumn{2}{|c|}{ Air Quality } \\
\hline & & & & & & PM10 & $\mathrm{SO}_{2}$ \\
\hline \multirow{2}{*}{ Transformer No. } & A1 & & & & & - & - \\
\hline & A2 & & & & & & \\
\hline B & & Total: 238 & & & & & \\
\hline \multirow{4}{*}{ Transformer No. } & B1 & 44 & & 60 & $\mathrm{~B}$ & \multirow{4}{*}{31} & \multirow{4}{*}{7} \\
\hline & B2 & 60 & & 55 & B & & \\
\hline & B3 & 69 & & 65 & $\mathrm{~B}$ & & \\
\hline & B4 & 65 & & 74 & $\mathrm{~B}$ & & \\
\hline $\mathrm{C}$ & & Total: 210 & & & & & \\
\hline \multirow{6}{*}{ Transformer No. } & $\mathrm{C} 1$ & 48 & & 66 & $\mathrm{C}$ & \multirow{2}{*}{52} & \multirow{2}{*}{15} \\
\hline & $\mathrm{C} 2$ & 32 & & 60 & $\mathrm{C}$ & & \\
\hline & $\mathrm{C} 3$ & 45 & & 61 & $\mathrm{C}$ & \multirow{2}{*}{79} & \multirow{2}{*}{15} \\
\hline & $\mathrm{C} 4$ & 18 & & 58 & $\mathrm{C}$ & & \\
\hline & C5 & 52 & & 72 & $\mathrm{C}$ & \multirow{2}{*}{14} & \multirow[b]{2}{*}{8} \\
\hline & C6 & 15 & & 48 & $\mathrm{D}$ & & \\
\hline $\mathrm{D}$ & & Total: 109 & & & & & \\
\hline \multirow{3}{*}{ Transformer No. } & D1 & 37 & \multirow{3}{*}{\multicolumn{2}{|c|}{83}} & $\mathrm{D}$ & \multirow{3}{*}{41} & \multirow{3}{*}{10} \\
\hline & D2 & $7(15 \mathrm{kV})$ & & & $\mathrm{D}$ & & \\
\hline & D3 & 65 & & & $\mathrm{C}$ & & \\
\hline
\end{tabular}

In localizing EV charge stations, the regional condition and some of their priorities were more important than the grid infrastructure on their locations. Therefore, they should develop their own location grid infrastructure. In most of the locations parking and public areas provide benefits from the financial and technical side, to create a battery bank and base for an EV charging station. In addition, all of them are explained in the "Selection of High Efficiency and Operational Locations" section of this paper. In this case, the transformers are not smart and the operations group cannot monitor the transformers status, so they do maintenance operations using technical data and by estimation. The transformers are replaced every 30 years and they reach $55 \sim 70 \%$ capacity during load peak times. These provide some information about the grid, such as transformers work condition. The ANSI/IEEE C57.96-1989 standards [27] recommend transformers be replaced every 20 years, if they have been run under ideal maintenance conditions. The transformers' life expectancy may be calculated by their insulation life equation, as illustrated below:

$$
\begin{gathered}
\log _{e} \text { life }(t)=A_{e}+\frac{B_{e}}{T} \\
\log _{10} \text { life }(t)=A_{10}+\frac{B_{10}}{T} .
\end{gathered}
$$

Based on Equations (8) and (9), Figures 5 and 6 illustrates the time expectancy curve, used in Equations (8) and (9). It shows that transforms, which age more than 20 years, have been in the best maintenance condition.

Figures 5 and 6 and the related Equations (Equation number 8 and 9) have shown that the transformers have been maintained and are in good condition (the grid has passed "Calculate Transformers Health by Load Summery, Age," term). 


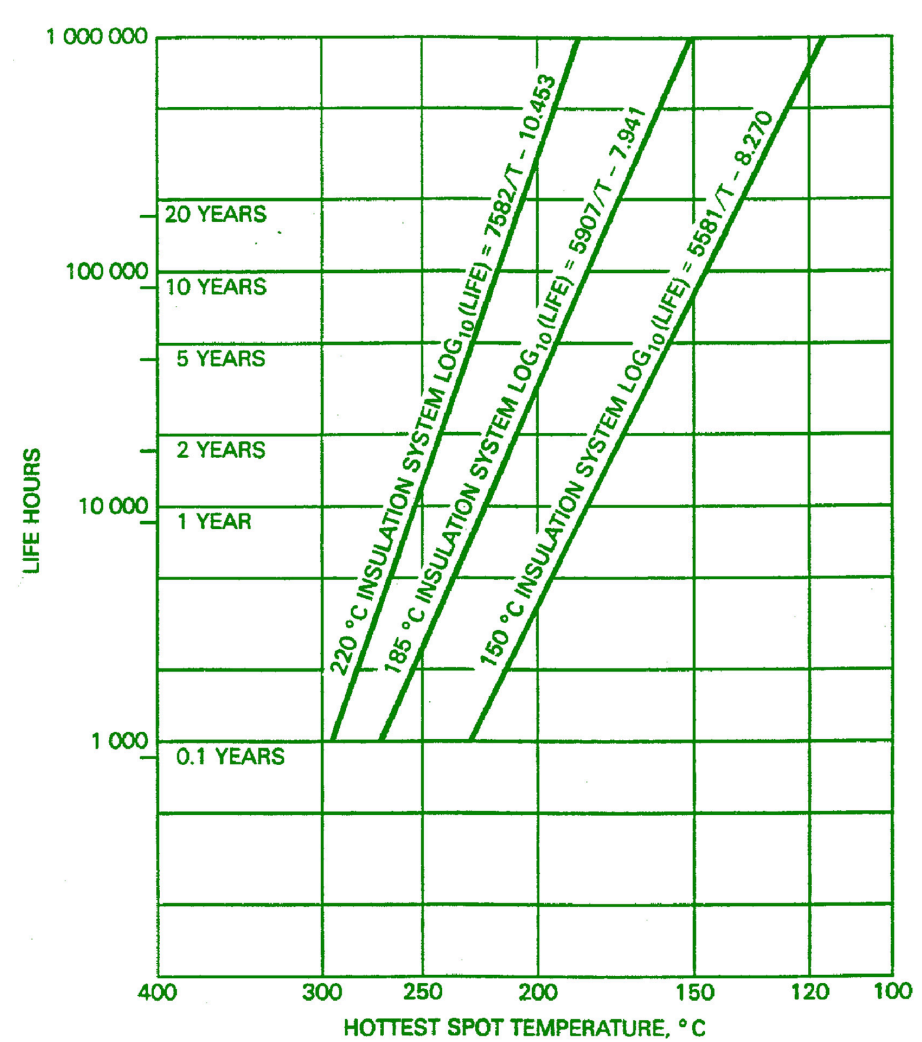

Figure 5. Life hours and hottest spot temperature ${ }^{\circ} \mathrm{C}$ in transformers by $\mathrm{LOG}_{10}$.

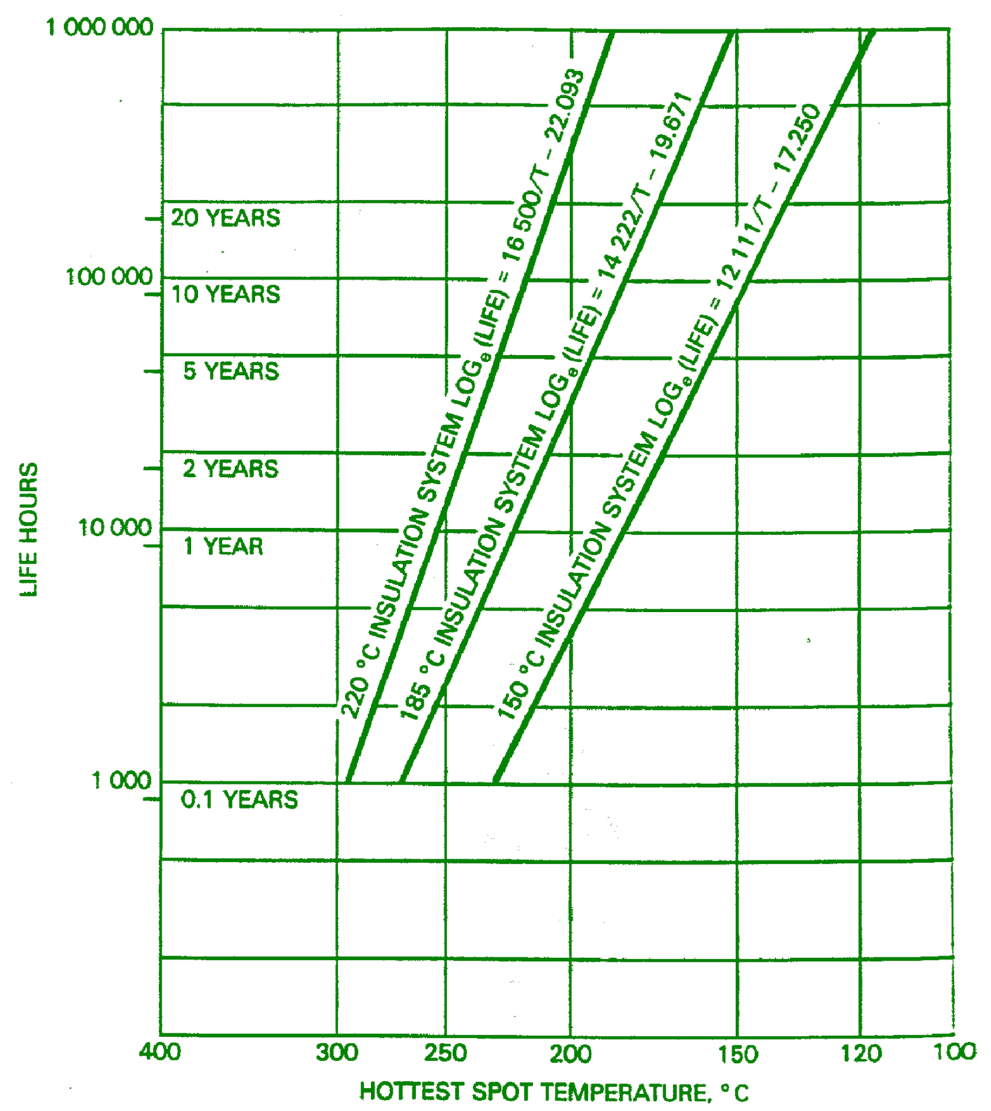

Figure 6. Life hours and hottest spot temperature ${ }^{\circ} \mathrm{C}$ in transformers by LOG10. 


\section{Assessment of Infrastructure}

As a crucial step for assessing the infrastructure, transformers' heal index should be assessed accurately by some standards and scoring system. Technical condition and their standards should cover their general status [28]. The technical and operational conditions are mentioned below:

- Technical conditions:

1. Transformer Parallelism Index

2. Transformer Reserve Index

3. Transformer Rated Power

- Operational conditions:

1. Main Health Index $\left(\mathrm{HI}_{\mathrm{m}}\right)$

2. Insulating Paper Health Index $\left(\mathrm{HI}_{\mathrm{iso}}\right)$

3. DGA Health Index $\left(\mathrm{HI}_{\mathrm{CH}}\right)$

4. Oil Health Index $\left(\mathrm{HI}_{\mathrm{oil}}\right)$

In this section of the paper, mentioned index is explained briefly.

\subsection{Technical Conditions}

\subsubsection{Transformer Parallelism Index}

If transformers are under load and analysis, the Transformer Parallelism Index is determined and shows when it pairs with another transformer, and which part of the grid demand is suitable for this parallelism. This value can change from 0 , where parallel transformers cannot work in parallel, or when they are not able to take charge of the connected equipment under the load, to 1 , where transformers can respond to the demand. The interval 0 to 1 has illustrated a percentage value in the transformer under the load that can response the maximum load power. This index is accepted from $120 \%$ to $140 \%$ in Brazil in accordance with the ONS NT 038/2014 standard [29] and is illustrated in Figure 7.

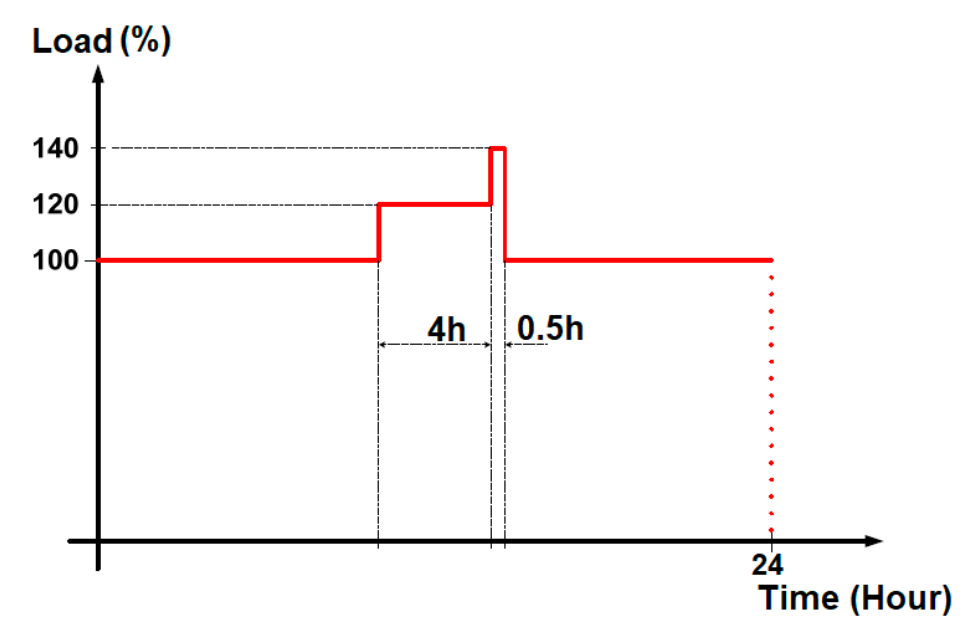

Figure 7. Acceptable Over Load by ONS NT 038/2014.

The Transformer Parallelism Index value is illustrated in Equations (10)-(14);

$$
\begin{cases}1 & \frac{T R P_{N y}}{T R P_{N x}}>\frac{f_{L}}{L_{\max }-f_{L}} \\ \frac{T R P_{N y}\left(L_{\max }-f_{L}\right)}{T R P_{N y} \cdot f_{L}} ; & \frac{T R P_{N y}}{T R P_{N x}} \leq \frac{f_{L}}{L_{\max }-f_{L}} \wedge 0<f_{L} \leq L_{\max } \\ 0 & f_{L}>L_{\max } \wedge f_{L}=0\end{cases}
$$




$$
\begin{gathered}
T R P_{N y}=\sum_{f_{L} \geq 0} \operatorname{TRP}-\operatorname{TRP}_{N x} \\
T R P_{N y} \geq 0, \forall y \in N \\
T R P_{N x} \geq 0, \forall x \in N
\end{gathered}
$$

\subsubsection{Transformer Reserve Index}

The Transformer Reserve Index is an index of transformers that can increase safety and reliability. It is a very important index in identifying whether power equipment can respond to normal failure and random interruption. However, charging stations, specifically fast charging stations, where production increase appears to produce impulse signals in their connected transformers and responses from transformers must be received. An example of this condition from real data has been explained in a study from São Miguel Island. Figure 8 has illustrated this fact in a curve by time and daily load [19].

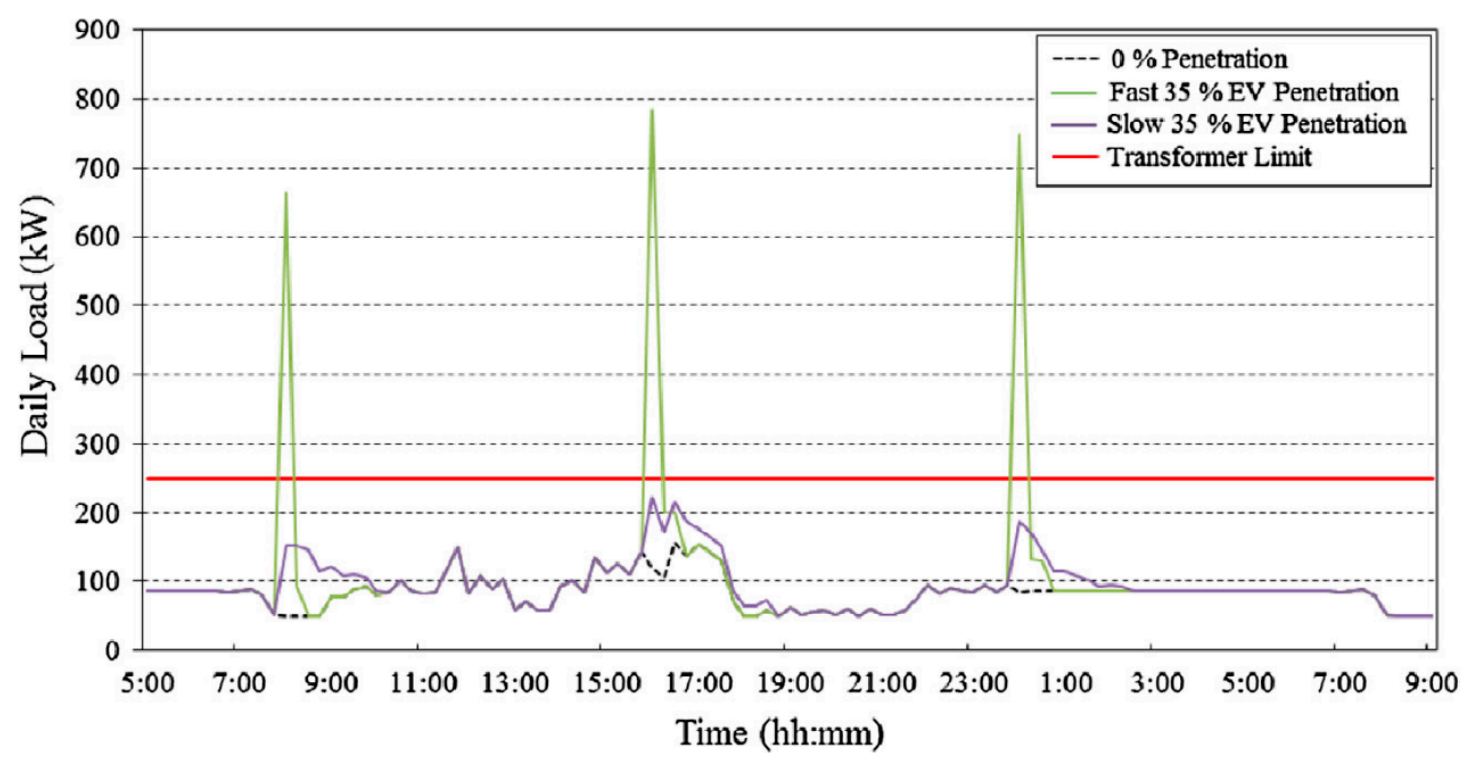

Figure 8. Transformer inputs in a fast and slow charge system by daily load versus time.

This problem can be partially solved by reserve index. To solve the mentioned issue, except transformer reserve, charging stations storage reserve is more sensible. Hence both of the reserves should increase logically.

\subsubsection{Transformer Rated Power}

The capacity of transformers is one of the important factors in receiving positive feedback from both the supply and demand side of the grid. The temperature in all aspects of the transformers depends on transformer rating. It must be stable in the operational area. As seen in the correlation between the life hour and temperature of transformer in Figure 5, transformer temperature can be a determinant in controlling the transformer conditions.

\subsection{Operational Conditions}

\subsubsection{Transformer's Main Health Index $\left(\mathrm{HI}_{\mathrm{m}}\right)$}

The transformer main health index has always been a useful factor in the transformer operational period. This index has been sensitive to temperature fluctuations, which changes in various ratios in the transformer life, so it depends on system summary. Transformers Main Health Index $\left(H I_{m}\right)$ is 
determined by the initial main health index reference point, which is named: $H I_{0}$. $H I_{m}$ is defined by Equations (15) and (16) mentioned below:

$$
\begin{gathered}
H I_{m}=H I_{0} \times e^{\beta \times\left(T_{2}-T_{1}\right)} \\
\beta=\frac{\ln 6.5-\ln 0.5}{T_{2}-T_{1}} .
\end{gathered}
$$

\subsubsection{Transformers' Insulating Paper Health Index $\left(\mathrm{HI}_{\text {iso }}\right)$}

Insulation paper in each transformer directly determines the efficiency and life of a transformer. The transformer condition can be illustrated by identifying this index. Transformers Insulating Paper Health Index $\left(\mathrm{HI}_{\text {iso }}\right)$ can be recognized by analyzing some gases, such as carbon monoxide and carbon dioxide, in the transformer which is damaged due to overheating over its lifetime. The Transformers Insulating Paper Health Index $\left(\mathrm{HI}_{\text {iso }}\right)$ is presented in Equation (17):

$$
\begin{aligned}
& H I_{i s o}=\omega_{1} H I_{C, O} \times \omega_{2} H I_{f u r} \\
& H I_{f u r}=3.344 \times\left(C_{f u r}\right)^{0.413} .
\end{aligned}
$$

From [30], where $C_{f u r}$ is content of furfural to determine, $H I_{f u r}$ is the index of it, from [28] $C_{f u r}=5$ means that the transformer is deteriorated and it can break down, in this condition $\mathrm{HI}_{f u r}=6.5$. On the other hand $C_{f u r}=0.01$ when it is newer and $\mathrm{HI}_{f u r}=0.5$. $\mathrm{HI}_{\mathrm{C}, \mathrm{O}}$ is defined by carbon monoxide and carbon dioxide gases analysis.

\subsubsection{Transformer's Dissolved Gas Analysis (DGA) Health Index $\left(\mathrm{HI}_{\mathrm{CH}}\right)$}

The Transformer's DGA health index $\left(\mathrm{HI}_{\mathrm{CH}}\right)$ is one of the important and regular tests to determine a power transformer's health. In this health index, the values of hydrogen $\left(\mathrm{H}_{2}\right)$, methane $\left(\mathrm{CH}_{4}\right)$, ethane $\left(\mathrm{C}_{2} \mathrm{H}_{6}\right)$, ethylene $\left(\mathrm{C}_{2} \mathrm{H}_{4}\right)$, acetylene $\left(\mathrm{C}_{2} \mathrm{H}_{2}\right)$, carbon monoxide $(\mathrm{CO})$, and carbon dioxide $\left(\mathrm{CO}_{2}\right)$ are analyzed in the transformer to estimate the power transformer's material condition, and consequently, the transformer's physical condition can be elaborated. The DGA health index $\left(\mathrm{HI}_{\mathrm{CH}}\right)$ is illustrated in Equation (19):

$$
H I_{C H}=\sum_{i=1}^{5} \omega_{i} \cdot F_{C, H}(i)
$$

where, $F_{C, H}$ is the quantity of transformer ageing, hydrocarbon gas factor function, and $\omega$ is the weight of presented gases.

\subsubsection{Transformer's Oil Health Index $\left(H I_{o i l}\right)$}

The Transformer's Oil Health index can have some errors, such as acid value, high fluctuation of voltage, micro water, and dielectric losses. Also, these factors are the result of the transformer's cooling system and the transformer topology, which is met in transformer oil. This index calculation is given in Equation (20):

$$
H I_{\text {oil }}=\sum_{i=1}^{4} \omega_{i} F_{\text {oil }}(i)
$$

where, $F_{\text {oil }}$ is the oil factor function, determined the hydrocarbon gas factor function and $\omega$ is the weight of presented gases. 


\section{Results}

In this section, we show that there are many factors which influence the distribution of charge stations. Air quality, transformer conditions, change infrastructure location, and local condition have illustrated that there are very important factors to feed the algorithms mentioned in the Introduction section of the paper. For example, the Gaussian distribution method in Equation (15) can give different results, depending on three factors, rather than two factors. Indeed, the factors change the distribution system variance and reference of their changes:

$$
f(x)=\frac{1}{\sqrt{2 \pi \sigma}} e^{-\frac{1}{2}\left(\frac{x-\mu}{\sigma}\right)^{2}}-\infty<x<+\infty .
$$

In addition, it is one of the distribution systems between different types. Today, most of the distribution systems work by multi-functional operations, based on the same system. The Genetic Algorithm is the most used algorithms for the same goal. However, they can work by different variables and functions. The control of each algorithm has its own special strategy and their responsibility efficiency depends on valid operational information from the location. Figure 9 has illustrated a hierarchy of input data for algorithms. In addition, operations in each algorithm will change if other priorities are used in their hierarchy.

Analyze Grid Stability by the Grid Control Size

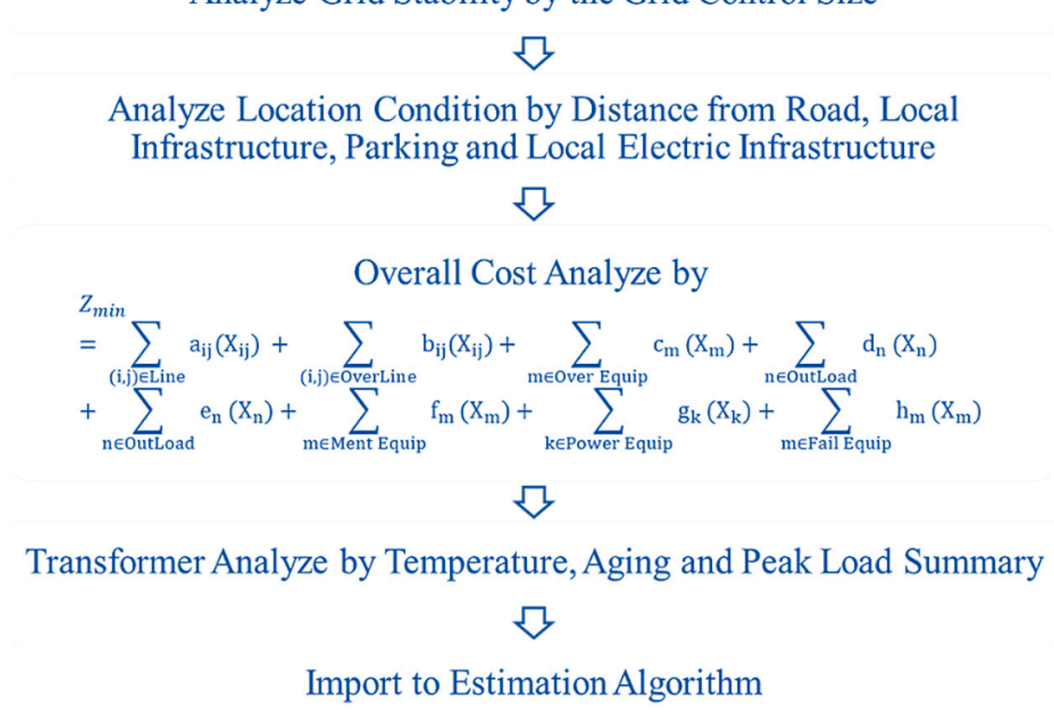

Figure 9. Hierarchy of algorithm input data.

In this case, the result of the "Estimation Algorithm" block depends on Turkish energy policy which involves long-term planning. According to the data mentioned in Table 1, two and location information, the GA is a reasonable method in creating a charging station point. Therefore, there are many drivers, reasons, and information, which can change algorithm targets. The information, which is issued by first data can be changed or improved by the GA algorithm. Figure 10 has mentioned an algorithm that was designed by the hierarchy presented in Figure 9. The algorithm has analyzed and sorted pure data to import on the main estimation algorithm. Firstly, the algorithm achieves location information, however, one of the algorithm targets is the charging station determination near the transportation road to reduce equipment faults during energy transmission. In the next step, the algorithm has been redeterminated in each fail loop or unsuccessful operation. In addition, the algorithm sorts each charging stations in some distance, which depends on grid and customers' needs. In the second step, the condition of the grid infrastructure has played a big role on algorithm output. In first technical command, it selects transformers, which have the highest reservoir capacity, so the transformers can absorb and transfer grid energy, and lacking in quality. The transformer 
should be selected by the highest criteria so that the charging stations, especially fast charging stations, behave differently than transformers' norm. In the second step, which contains the analysis of technical condition, the determination of the points have been issued by their previous technical conditions. Transformers' conditions can be calculated by temperature or maintenance information.

According to above-mentioned operations, three points (B, D and C) have been determined to be the locations for building EV fast charging stations in Ankara. There are sufficient reasons to select the mentioned transformer centers, by the time they have some difference between mentioned points. Some local infrastructure and transformer responsibility factors have different factors which can be solved by some location problem using GA.

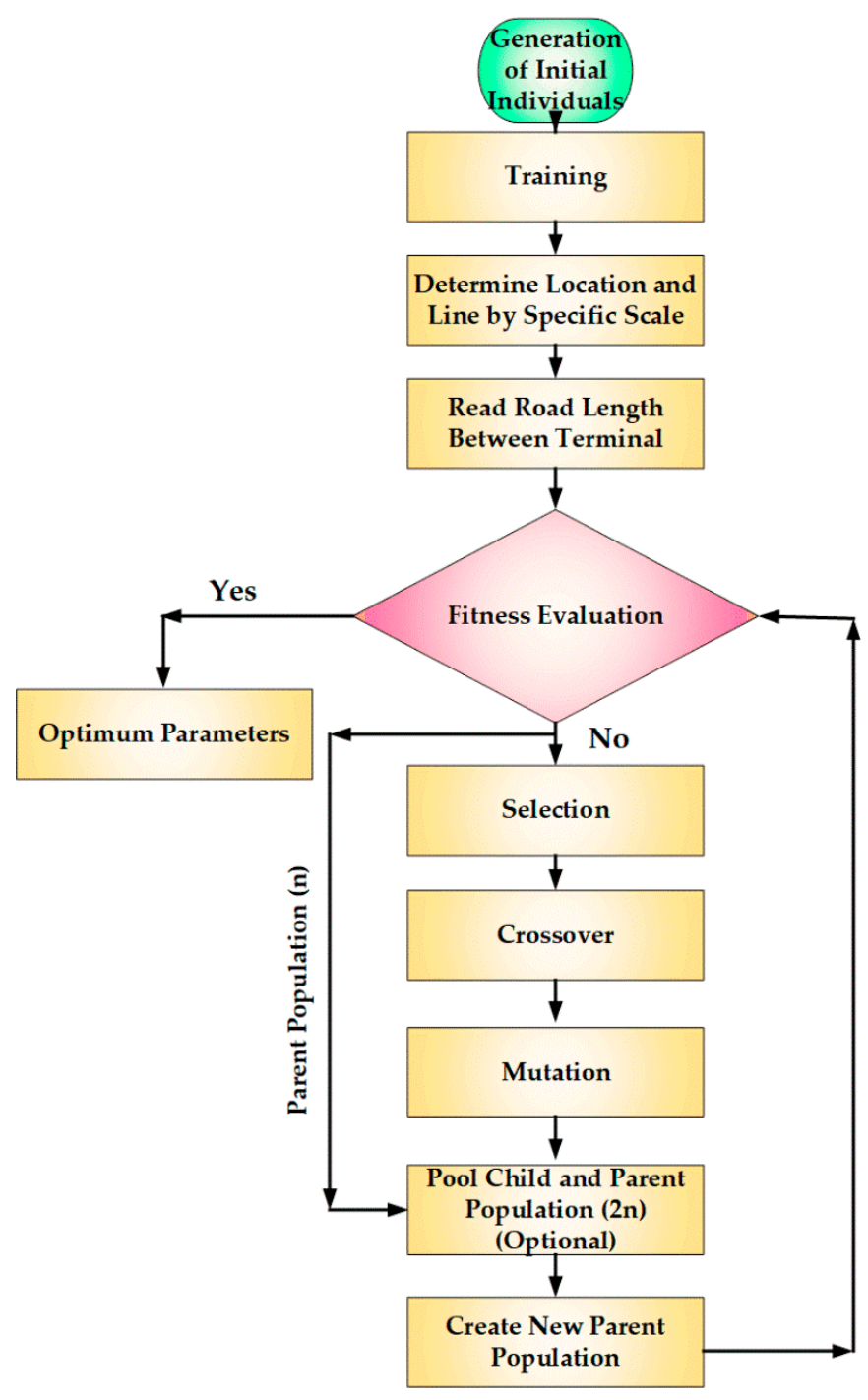

Figure 10. Flow chart of Genetic Algorithm (GA) estimation method.

Using the above-mentioned factors, the designers should give some scores to parameters, in order to determine factors' priorities, then, their data might be ready to input on estimating algorithms. For example, in GA it can be solved by the Genetic Algorithm shown in Figure 10.

According to the above flowchart, the algorithm can adapt in most of the estimating algorithms. For three areas, marked B, C, and D, several sets of locations and electric infrastructure have been arranged as chromosome structures, shown in Table 3. Six chromosome sets are based on the flowchart in Figure 10. The locations are sorted based on distance (a gene), local infrastructure (b gene), parking (c gene), and electric infrastructure (d gene). The generations are derived according to 
low loads, ageing, and transformer capacity transformer index of the mentioned areas respectively. A maximum of 30 locations have been considered to satisfy the objective function mentioned as:

$$
F_{o b j}=a+2 b+3 c+4 d-30 .
$$

Table 3. Chromosome structure for aforementioned locations with their corresponding areas (termed as B, C, and D).

\begin{tabular}{ccccc}
\hline & a & b & c & d \\
\hline & Gen_1 & Gen_2 & Gen_3 & Gen_4 \\
\hline \multicolumn{5}{c}{$\Leftarrow$ Chromosome Length $\Rightarrow$} \\
\hline $\begin{array}{c}\text { Electric } \\
\text { Infrastructure }\end{array}$ & 9 & Area B & 12 \\
\hline Location & 27 & 6 & 27 & 9 \\
\hline $\begin{array}{c}\text { Electric } \\
\text { Infrastructure }\end{array}$ & 6 & Area C & 15 & 27 \\
\hline Location & 18 & 24 & 9 & 21 \\
\hline $\begin{array}{c}\text { Electric } \\
\text { Infrastructure }\end{array}$ & 27 & 24 & 24 & 27 \\
\hline
\end{tabular}

Six chromosome have been created by location and infrastructure genes. The calculation of determination of the fittest chromosomes have been illustrated in Table 4 .

Table 4. Determination of fitness function and probability for the first generator.

\begin{tabular}{|c|c|c|c|c|c|}
\hline$i$ & Chromosome i[a;b;c;d] & F_obj[i] & Fitness $[i]=\frac{1}{F_{o b j i i]}}+1$ & $P[i]=\frac{\text { Fitness }[i]}{\text { Total_Fitness }}$ & $\begin{array}{c}\text { Cumulative } \\
\text { Probability, } C[i]\end{array}$ \\
\hline 1 & {$[27 ; 24 ; 27 ; 12]$} & $\begin{array}{c}\left(\left(27+\left(2^{*} 24\right)+\right.\right. \\
\left(3^{*} 27\right)+\left(4^{*} 12\right) \\
-30))=174\end{array}$ & 0.005714285 & 0.131445255 & 0.131445255 \\
\hline 2 & {$[09 ; 06 ; 15 ; 09]$} & $\begin{array}{c}\left(\left(9+\left(2^{*} 6\right)+\right.\right. \\
\left(3^{*} 15\right)+\left(4^{*} 9\right)- \\
30))=072\end{array}$ & 0.013698630 & 0.315108524 & 0.446553779 \\
\hline 3 & {$[06 ; 24 ; 09 ; 27]$} & $\begin{array}{c}((6+(2 * 24)+ \\
(3 * 9)+\left(4^{*} 27\right)- \\
30))=159\end{array}$ & 0.006250000 & 0.143768265 & 0.590322044 \\
\hline 4 & {$[18 ; 24 ; 24 ; 21]$} & $\begin{array}{c}\left(\left(18+\left(2^{*} 24\right)+\right.\right. \\
\left(3^{*} 24\right)+\left(4^{*} 21\right) \\
-30))=192\end{array}$ & 0.005181347 & 0.119186123 & 0.709508167 \\
\hline 5 & {$[27 ; 15 ; 06 ; 27]$} & $\begin{array}{c}\left(\left(27+\left(2^{*} 15\right)+\right.\right. \\
\left(3^{*} 6\right)+\left(4^{*} 27\right)- \\
30))=153\end{array}$ & 0.006493506 & 0.149369615 & 0.85887778 \\
\hline \multirow[t]{2}{*}{6} & {$[15 ; 21 ; 21 ; 18]$} & $\begin{array}{c}\left(\left(15+\left(2^{*} 21\right)+\right.\right. \\
(3 * 21)+\left(4^{*} 18\right) \\
-30))=162\end{array}$ & 0.006134969 & 0.141122216 & $0.999999998 \approx 1.0$ \\
\hline & & & $\begin{array}{c}\text { Total_Fitness }= \\
0.043472737\end{array}$ & & \\
\hline
\end{tabular}


If the random values ranging from $0-1$ are initiated and if $C[1]<R[1]<C[2]$, then chromosome [2] can be set as the new population for the next generation.

$$
R=[0.37,0.08,0.971,0.829,0.735,0.359]
$$

By those random patterns, new chromosomes have listed in below:

Chromosomes 2: $[09 ; 06 ; 15 ; 09]$ as New Chromosome 1

Chromosomes 1: $[27 ; 24 ; 27 ; 12]$ as New Chromosome 2

Chromosomes 6: $[15 ; 21 ; 21 ; 18]$ as New Chromosome 3

Chromosomes 5: $[27 ; 15 ; 06 ; 27]$ as New Chromosome 4

Chromosomes 5: $[27 ; 15 ; 06 ; 27]$ as New Chromosome 5

Chromosomes 2: $[09 ; 06 ; 15 ; 09]$ as New Chromosome 6

Considering a crossover-rate of $25 \%$, if the corresponding value of $R[k]$ is less than the rate, the chromosome will be considered as the parent chromosome. For an array of random number:

$$
R=[0.518,0.224,0.108,0.383,0.071,0.481]
$$

By the new randomization and chromosomes, the parents can be presented as below:

Chromosome 2: [27; 24; 27; 12]

Chromosome 3: $[15 ; 21 ; 21 ; 18]$

Chromosome 5: $[27 ; 15 ; 06 ; 27]$

By the random numbers that have given in crossover section, new set of crossovers will be:

$$
\begin{aligned}
& \text { Chromosome [2] } \times \text { chromosome [3] } \\
& \text { Chromosome [2] } \times \text { chromosome [5] } \\
& \text { Chromosome [3] } \times \text { chromosome [5] }
\end{aligned}
$$

Chromosome 2: Chromosome $2 \times$ Chromosome $3=[27 ; 24 ; 27 ; 12] \times[15 ; 21 ; 21 ; 18]=[27 ; 24 ; 21 ; 18]$

Chromosome 3: Chromosome $3 \times$ Chromosome $5=[15 ; 21 ; 21 ; 18] \times[27 ; 15 ; 06 ; 27]=[15 ; 21 ; 06 ; 27]$

Chromosome 5: Chromosome $5 \times$ Chromosome $2=[27 ; 15 ; 06 ; 27] \times[27 ; 24 ; 27 ; 12]=[27 ; 15 ; 27 ; 12]$

New chromosomes after the crossover process have been illustrated below:

Chromosome [1]: [09; 06; 15; 09]

Chromosome [2]: [27; 24; 21; 18]

Chromosome [3]: [15; 21; 06; 27]

Chromosome [4]: [27; 15; 06; 27]

Chromosome [5]: [27; 15; 27; 12]

Chromosome [6]: [09; 06; 15; 09] 
For a mutation rate of $10 \%$, as there are 24 genes in total, the number of mutation will be $0.1 \times 24=2.4$, which can be equated to 2 . Thus, the mutated genes are marked in bold.

Chromosome [1]: [09; 06; 15; 09]

Chromosome [2]: $[27 ; 24 ; 21 ; 18]$

Chromosome [3]: [15; 21; 06; 27]

Chromosome [4]: [27; 15; 06; 27]

Chromosome [5]: $[27 ; 15 ; 27 ; 12]$

Chromosome [6]: [09; 06; 15; 09]

The mutated genes must be replaced by random numbers from 0-30 to obtain the new set of chromosomes to proceed for iterating in the next generation. If the numbers be 10, 15, 20 and 25 respectively, the new chromosomes will be:

Chromosome [1]: [09; 10; 15; 09]

Chromosome [2]: [27; 24; 21; 18]

Chromosome [3]: [15; 21; 15; 27]

Chromosome [4]: [27; 15; 20; 27]

Chromosome [5]: [27; 15; 27; 12]

Chromosome [6]: [09; 25; 15; 09]

This is the chromosomes of generation one of the algorithm. The process will be iterated until the value of $a, b, c$, and $d$ meets the optimum value to satisfy the equation. After iterating for 5 generations, the evolution fitness chart will be as represented in Figure 11:

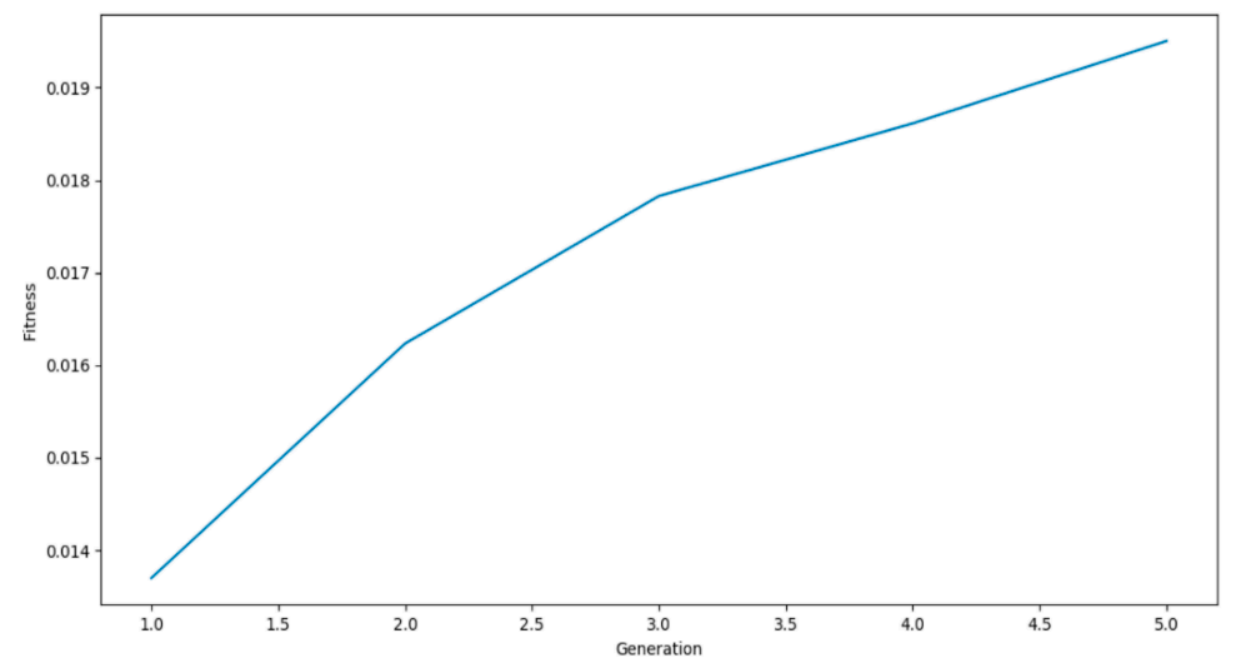

Figure 11. Evolution fitness curve showing gradual increase in fitness value corresponding to the generation.

The algorithm considered three areas, and after selecting several locations according to the aforementioned parameters (Figure 9), sorted the data into four segments. However, by creating six chromosomes, the algorithms mentioned in Figure 10 were followed to obtain the first generation of the chromosome. The aim was to attain the best value for the variables in the objective function, so that the optimum location for the charging station can be determined. Fitness value for each corresponding 
generation is calculated, and as it can be seen, fitness increased with each generation, indicating the success of the algorithm. The higher the value of fitness, the better the algorithm. Thus, after several iterations, the optimal locations in these areas were determined in Ankara metropolitan, as the locations illustrated in Figure 12.

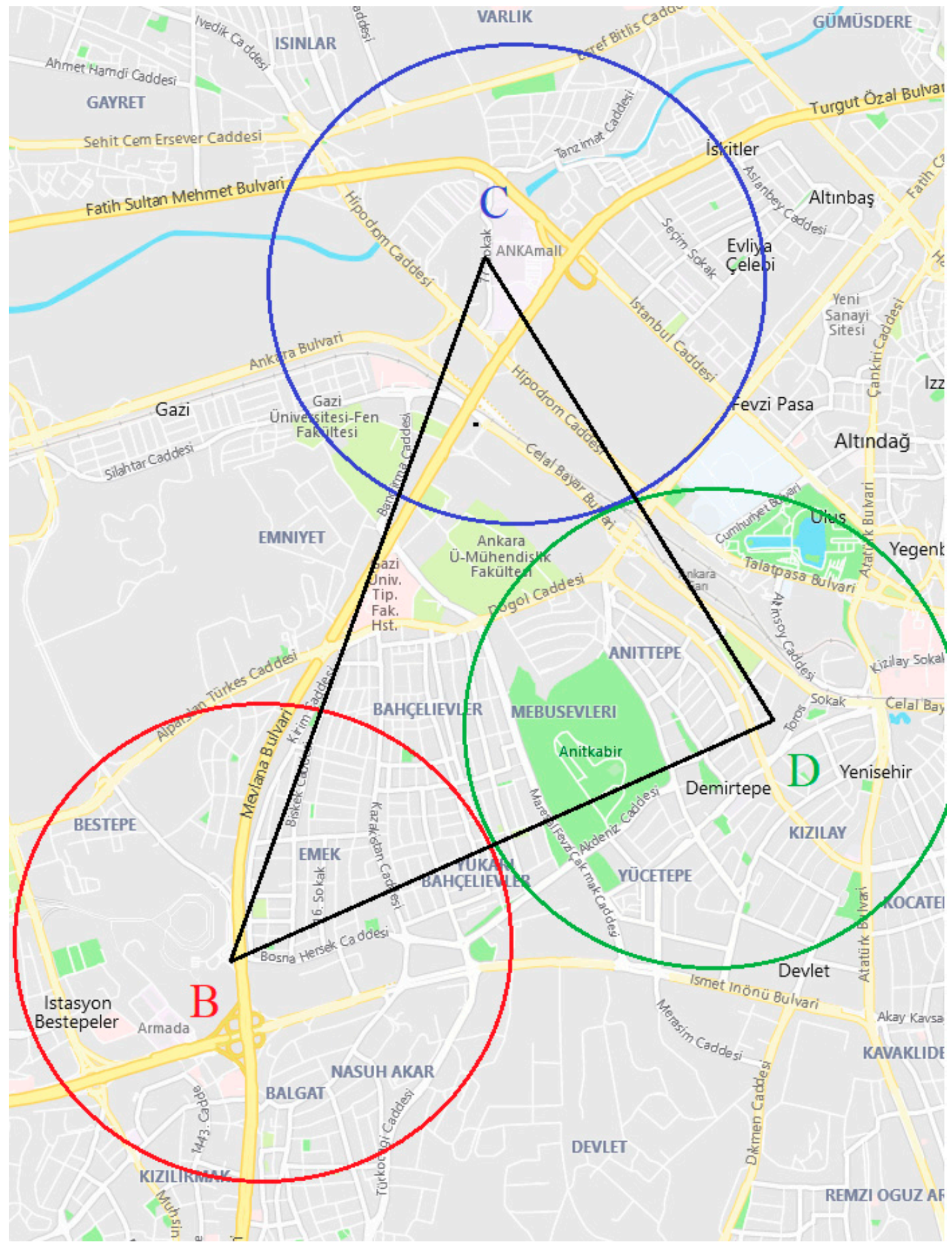

Figure 12. Selected points in Ankara (By Bing map). 


\section{Conclusions}

In this research, an algorithm has been provided, which explains the hierarchy of the way the locations of EV charging stations should be determined by experimental exemplification from some literatures and the Ankara case study. The algorithm has been made up of three sections: Finding a location by specifications of the grid infrastructure, categorizing the capacity of transformers, and transformer analysis. It has been created especially for grid designers who have recently started to determine the points for charging stations in cities. In the Ankara case study, considerations for stability of the grid has been eliminated from the algorithm, because the grid can be considered to be stable for having adequate reserved power from neighboring control areas. The novelty of this research is the assertion that some limited parameters can show grid equipment conditions in the past to solve grid problems. Finally, this research has built a congruency and connection between the algorithm theories, programming languages, and practical strategy for the grid. The research has indicated that the transformers' condition, electric infrastructure, budget, and various other aspects, which are influenced by energy consumption, are important factors in approaching this issue. Furthermore, this research has shown that the maintenance history of the grid equipment and infrastructure are the key points in determining the locations of electric vehicles charge stations. The optimum locations have been determined using a Genetic Algorithm, which has been mathematically interpreted and analyzed. EVs and storage are garnering interests to the People's Republic of China, Europe, Japan, the United States of America, and recently, it has caught India's attention for the purpose of decreasing GHG emission as soon as possible. Science and technology is improving every second. This algorithm can be a stepping stone in the field of technology, which is used for autonomous systems on storages supplied by the grid or DC link.

Author Contributions: All authors contributed equally to the research activities and for its final presentation as a full manuscript.

Funding: No source of funding was attained for this research activity.

Acknowledgments: The authors would like to acknowledge the support and technical expertise received from the center for Bioenergy and Green Engineering, Department of Energy Technology, Aalborg University, Esbjerg, Denmark, which made this publication possible.

Conflicts of Interest: The authors declare no conflict of interest.

\section{Abbreviations}

$\begin{array}{ll} & \text { Description } \\ z & \text { The objective function of transmission and distribution cost } \\ X_{i, j} & \text { The transmission power flow from substations } \\ X_{m} & \text { The electric power flow in apparatus } \mathrm{m} \\ X_{n} & \text { The outage power of load } \mathrm{n} \\ a_{i, j} & \text { The cost of the transmission and distribution loss during normal operation } \\ b_{i, j} & \text { The cost of the transmission and distribution loss during overload operation } \\ c_{m} & \text { The damage caused by a shortened service life due to overload operation } \\ d_{n} & \text { The customer's outage cost } \\ e_{n} & \text { The supplier's outage cost } \\ f_{m} & \text { The maintenance cost } \\ g_{m} & \text { The fuel cost of power apparatus } \\ h_{m} & \text { The repair cost of failed apparatus } \\ \text { Line } & \text { The sets of transmission lines } \\ \text { OverLine } & \text { The sets of overload lines } \\ \text { OutLoad } & \text { The sets of outage loads } \\ \text { MentEquip } & \text { The set of apparatus in the transmission and distribution system } \\ \text { FailedEquip } & \text { The set of failed apparatus in the transmission and distribution system }\end{array}$




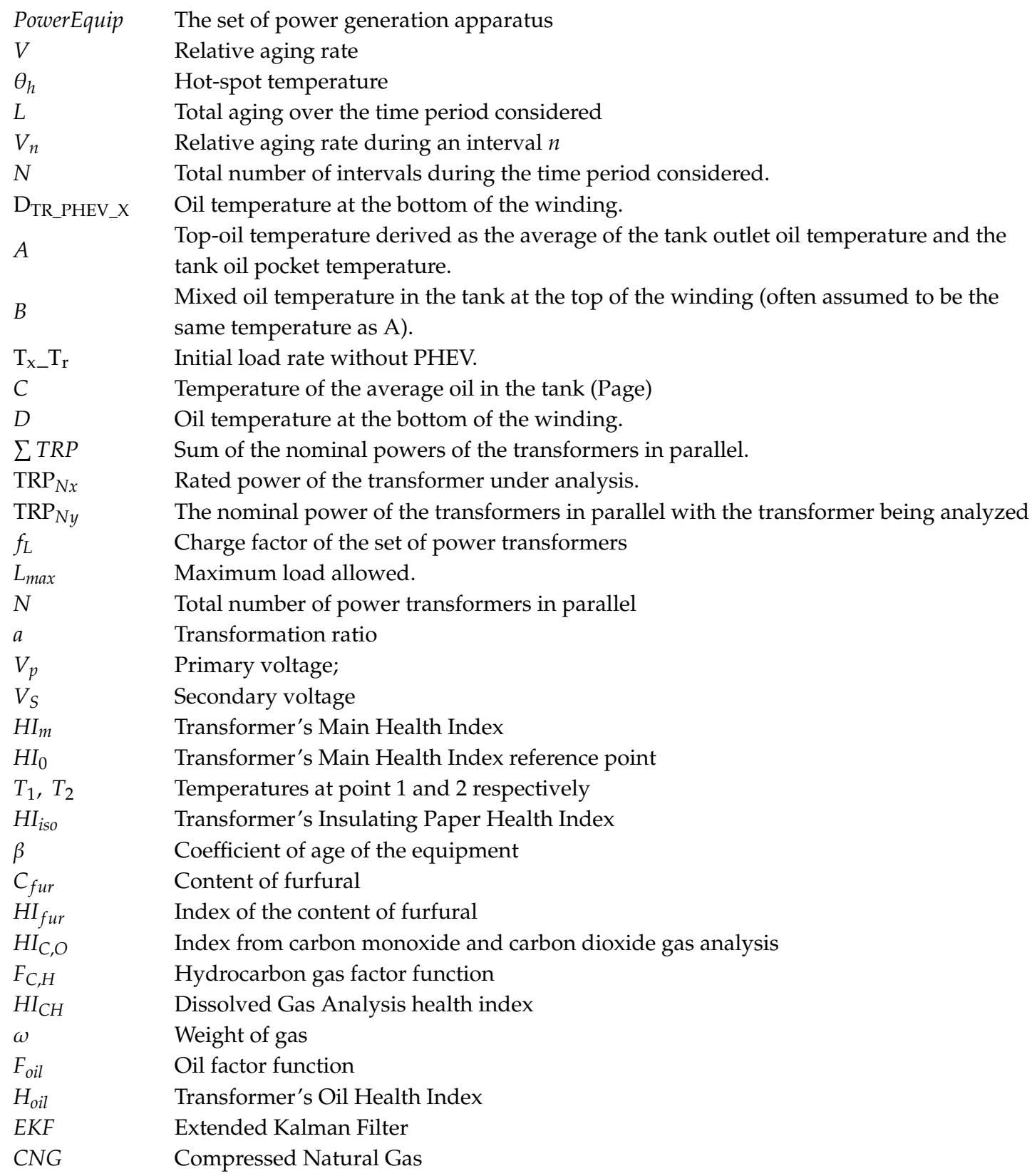

\section{References}

1. Harighi, T.; Bayindir, R.; Padmanaban, S.; Mihet-Popa, L.; Hossain, E. An Overview of Energy Scenarios, Storage Systems and the Infrastructure for Vehicle-to-Grid Technology. Energies 2018, 11, 2174. [CrossRef]

2. Harighi, T.; Bayindir, R. Load Estimation Use in Electric Vehicle Charge Station Coordination in Different Node and Definite Area. In Proceedings of the 2018 International Conference on Smart Grid (icSmartGrid), Nagasaki, Japan, 4-6 December 2018.

3. Wang, Q.; Wang, J.; Zhao, P.; Kang, J.; Yana, F.; Dua, C. Correlation between the model accuracy and model-based SOC estimation. Electrochim. Acta 2017, 228, 146-159. [CrossRef]

4. Østergaard, P.A. Reviewing EnergyPLAN simulations and performance indicator applications in EnergyPLAN simulations. Appl. Energy 2015, 154, 921-933. [CrossRef]

5. Farzaneh, H.; Doll, C.N.; Oliveira, J.A.P.D. An integrated supply-demand model for the optimization of energy flow in the urban system. J. Clean. Prod. 2016, 114, 269-285. [CrossRef]

6. Li, Y.; Davis, C.; Lukszo, Z.; Weijnen, M. Electric vehicle charging in China's power system: Energy, economic and environmental trade-offs and policy implications. Appl. Energy 2016, 173, 535-554. [CrossRef] 
7. Wang, Y.W.; Lin, C.C.; Lee, T.J. Electric vehicle tour planning. Trans. Res. Part D 2018, 63, 121-136. [CrossRef]

8. Misra, S.; Bera, S.; Ojha, T.; Mouftah, H.; Anpalagan, A. ENTRUST: Energy trading under uncertainty in smart grid systems. Comput. Netw. 2016, 110, 232-242. [CrossRef]

9. Meng, J.; Mu, Y.; Jia, H.; Wu, J.; Yu, X.; Qu, B. Dynamic frequency response from electric vehicles considering travelling behavior in the Great Britain power system. Appl. Energy 2016, 162, 966-979. [CrossRef]

10. He, Y.; Kockelman, K.M.; Perrine, K.A. Optimal locations of U.S. fast charging stations for long-distance trip completion by battery electric vehicles. J. Clean. Prod. 2019, 214, 452-461. [CrossRef]

11. Zarandi, M.F.; Davari, S.; Sisakht, S.H. The large scale maximal covering location problem. Sci. Iran. 2011, 18, 1564-1570. [CrossRef]

12. Heydarian-Forushani, E.; Golshan, M.; Shafie-khah, M. Flexible interaction of plug-in electric vehicle parking lots for efficient wind integration. Appl. Energy 2016, 179, 338-349. [CrossRef]

13. Zhou, B.; Yao, F.; Littler, T.; Zhang, H. An electric vehicle dispatch module for demand-side energy participation. Appl. Energy 2016, 177, 464-474. [CrossRef]

14. Mozafar, M.R.; Moradi, M.H.; Amini, M.H. A Simultaneous Approach for Optimal Allocation of Renewable Energy Sources and Charging Stations based on Improved GA-PSO Algorithm. Sustain. Cities Soc. 2017, 32, 627-637. [CrossRef]

15. Hu, D.; Zhang, J.; Zhang, Q. Optimization design of electric vehicle charging stations based on the forecasting data with service balance consideration. Appl. Soft Comput. J. 2019, 75, 215-226. [CrossRef]

16. Bing Map. Available online: https://www.bing.com/maps (accessed on 8 April 2019).

17. EnerjiSA. Başkent Elektrik Dağıtım, A.Ş. Available online: https://www.enerjisa.com.tr/en/about-enerjisa/ our-operations/distribution/baskent-edas (accessed on 5 September 2019).

18. Yılmaz, A. Enerji Atlası. Available online: https://www.enerjiatlasi.com/sehir/ankara/ (accessed on 8 April 2019).

19. Godina, R.; Rodrigues, E.; Paterakis, N.; Erdinc, O.; Catalão, J. Innovative impact assessment of electric vehicles charging loads on distribution transformers using real data. Energy Convers. Manag. 2016, 120, 206-216. [CrossRef]

20. Clairand, J.M.; Rodríguez-García, J.; Álvarez-Bel, C. Smart Charging for Electric Vehicle Aggregators considering Users Preferences. IEEE Trans. J. 2018, 6, 54624-54635. [CrossRef]

21. Munoz, E.R.; Razeghi, G.; Zhang, L.; Jabbari, F. Electric vehicle charging algorithms for coordination of the grid and distribution transformer levels. Energy 2016, 113, 930-942. [CrossRef]

22. Zou, S.; Hiskens, I.; Ma, Z. Consensus-based coordination of electric vehicle charging considering transformer hierarchy. Control Eng. Pract. 2018, 80, 138-145. [CrossRef]

23. Shokrzadeh, S.; Ribberink, H.; Rishmawi, I.; Entchev, E. A simplified control algorithm for utilities to utilize plug-in electric vehicles to reduce distribution transformer overloading. Energy 2017, 133, 1121-1131. [CrossRef]

24. Hanai, M.; Kojima, H.; Hayakawa, N.; Shinoda, K.; Okubo, H. Integration of Asset Management and Smart Grid with Intelligent Grid Management System. IEEE Trans. Dielectr. Electr. Insul. 2013, 20, 2195-2202. [CrossRef]

25. Godina, R.; Rodrigues, E.; Shafie-khah, M.; Matias, J.; Catalão, J. Overloading Analysis of an Industrial Client Distribution Transformer in a Portuguese Island. In 2016 IEEE International Energy Conference (ENERGYCON); IEEE: Leuven, Belgium, 2016.

26. Turker, H.; Bacha, S.; Chatroux, D.; Hably, A. Low-Voltage Transformer Loss-of-Life Assessments for a High Penetration of Plug-In Hybrid Electric Vehicles (PHEVs). IEEE Trans. Power Deliv. 2012, 27, 1323-1331. [CrossRef]

27. Linsley, K.; White, C.H. IEEE Guide for Loading Dry-Type Distribution and Power Transformers; IEEE: New York, NY, USA, 1989.

28. Schmitz, W.I.; Feil, D.L.P.; Canha, L.N.; Abaide, A.R.; Marchesan, T.B.; Carraro, R. Operational vulnerability indicator for prioritization and replacement of power transformers in substation. Electr. Power Energy Syst. 2018, 102, 60-70. [CrossRef] 
29. Standard, B. NT ONS 038 2014-Transformadores-Ensaios e Elevação de Temperatura em Sobrecarga; Operador Nacional do Sistema Elétrico: Rio de Janeiro, Brazil, 2014.

30. En-Wen, L.; Bin, S. Transformer health status evaluation model based on multi-feature factors. In 2014 International Conference on Power System Technology; IEEE: Chengdu, China, 2014.

(C) 2019 by the authors. Licensee MDPI, Basel, Switzerland. This article is an open access article distributed under the terms and conditions of the Creative Commons Attribution (CC BY) license (http://creativecommons.org/licenses/by/4.0/). 